\title{
Exploring the Pathogenicity of Pseudomonas brassicacearum Q8r1-96 and Other Strains of the Pseudomonas fluorescens Complex on Tomato
}

\author{
Mingming Yang, ${ }^{1, \dagger}$ Dmitri V. Mavrodi, ${ }^{2}$ Olga V. Mavrodi, ${ }^{2}$ Linda S. Thomashow, ${ }^{3}$ and David M. Weller ${ }^{3, \dagger}$ \\ ${ }^{1}$ Department of Agronomy, Northwest A\&F University, Yangling 712100, P. R. China \\ ${ }^{2}$ School of Biological, Environmental, and Earth Sciences, The University of Southern Mississippi, Hattiesburg, MS 39406, \\ U.S.A. \\ ${ }^{3}$ U.S. Department of Agriculture, Agricultural Research Service, Wheat Health, Genetics and Quality Research Unit, Pullman, \\ WA 99164-6430, U.S.A.
}

\begin{abstract}
Pseudomonas brassicacearum and related species of the $P$. fluorescens complex have long been studied as biocontrol and growth-promoting rhizobacteria involved in suppression of soilborne pathogens. We report here that $P$. brassicacearum Q8r1-96 and other 2,4-diacetylphloroglucinol (DAPG)-producing fluorescent pseudomonads involved in take-all decline of wheat in the Pacific Northwest of the United States can also be pathogenic to other plant hosts. Strain Q8r1-96 caused necrosis when injected into tomato stems and immature tomato fruits, either attached or removed from the plant, but lesion development was dose dependent, with a minimum of $10^{6} \mathrm{CFU} \mathrm{ml}{ }^{-1}$ required to cause visible tissue dam-

concentration of $10^{8} \mathrm{CFU} \mathrm{ml}{ }^{-1}$, were significantly less virulent, but not consistently, as compared with the wild-type strain. However, a DAPG-deficient phlD mutant of Q8r1-96 was significantly and consistently less virulent as compared with the wild type. Strain Q8r1-96acc, engineered to over express ACC deaminase, caused a similar amount of necrosis as the wild type. Cell-free culture filtrates of strain Q8r1-96 and pure DAPG also cause necrosis in tomato fruits. Our results suggest that DAPG plays a significant role in the ability of Q8r1-96 to cause necrosis of tomato tissue, but other factors also contribute to the pathogenic properties of this organism.
\end{abstract} age. We explored the relative contribution of several known plantmicrobe interaction traits to the pathogenicity of strain Q8r1-96. Type III secretion system (T3SS) mutants of Q8r1-96, injected at a
Keywords: prokaryotes, vegetables, 2,4-diacetylphloroglucinol, ACC deaminase, tomato, Pseudomonas
Pseudomonas brassicacearum and related species of the $P$. fluorescens complex are ubiquitous soil microorganisms that have long been studied for their beneficial plant growth-promoting and biocontrol properties (Raaijmakers and Weller 1998; Schlatter et al. 2017). For example, strains of $P$. brassicacearum (formerly $P$. fluorescens genotype D) are biocontrol agents against soilborne pathogens and are responsible for take-all decline (TAD), a natural suppression of take-all disease in monoculture wheat fields of the Pacific Northwest (PNW) of the United States (Schlatter et al. 2017). However, these organisms have also been reported as "quasi" or minor pathogens that blur the boundaries between saprophytism and parasitism and under certain conditions can cause disease (Belimov et al. 2007; Brazelton et al. 2008; Kwak et al. 2012). For example, P. brassicacearum Q8r1-96 reduced the germination of wheat seeds and caused lesions

${ }^{\dagger}$ Corresponding authors: M. M. Yang; myang@ @wsuaf.edu.cn; D. M. Weller; david.weller@usda.gov

Mention of trade names or commercial products in this publication is solely for the purpose of providing specific information and does not imply recommendation or endorsement by the U.S. Department of Agriculture. USDA is an equal opportunity provider and employer.

Funding: This research was supported by a grant from the O. A. Vogel Wheat Research Fund of Washington State University, Pullman, Washington, U.S.A. M. Yang was supported by a scholarship from the China Scholarship Council (201806305044).

*The $\boldsymbol{e}$-Xtra logo stands for "electronic extra" and indicates that one supplementary figure is published online.

The author(s) declare no conflict of interest.

Accepted for publication 11 October 2019.

This article is in the public domain and not copyrightable. It may be freely reprinted with customary crediting of the source. The American Phytopathological Society, 2020. on wheat roots in a cultivar- and dose-dependent manner (Kwak et al 2012; Yang et al. 2018). P. brassicacearum strains Am3 and 520-1 have either growth-promoting or pathogenic effects on tomato depending on the dose and environmental conditions (Belimov et al. 2007). Inoculation of unripe tomatoes with Am3R or 520-1 resulted in necrosis of the fruits; however, these strains also induced tomato root elongation and plant growth due to the presence of 1aminocyclopropane-1-carboxylate (ACC) deaminase, which hydrolyzes the immediate precursor of the plant hormone ethylene (Belimov et al. 2007; Glick 1995). Belimov et al. (2007) suggested that the ACC deaminase of Am3 helps to promote growth in tomato by masking the pathogenic properties of this bacterium.

Type III secretion systems (T3SSs) play an essential role in the interaction of pathogenic and symbiotic gram-negative bacteria with their plant hosts. The T3SS-mediated secretion of effector molecules into host cells helps pathogens to suppress the plant defense response system and favor infection (Cornelis 2010; Mavrodi et al. 2011; Tampakaki 2014). The genome of P. brassicacearum Q8r1-96 carries genes encoding a functional T3SS and effectors, many of which have homologs in the plant pathogen P. syringae (Loper et al. 2012). Although the type III effectors of Q8r1-96 were fully functional and capable of suppressing PAMP- and effectortriggered plant immunity, the inactivation of genes encoding structural components of the T3SS apparatus did not reduce the rhizosphere competence and biocontrol properties (Mavrodi et al. 2011). Yang et al. (2018) later found that the same TTSS mutants were identical to wild type Q8r1-96 in ability to reduce seed germination and root growth of wheat.

2,4-diacetylphloroglucinol (DAPG) is an antibiotic produced by $P$. brassicacearum and some other members of the $P$. fluorescens complex (Loper et al. 2012). It has broad spectrum antibiotic activity and can inhibit organisms ranging from viruses, bacteria, and fungi to higher plants and mammalian cells (Brazelton et al. 2008; Haas and Keel 2003; Kwak et al. 2011; Maurhofer et al. 1995; Yang et al. 2018). Studies in Saccharomyces cerevisiae revealed that DAPG has a complex mode of action and affects target organisms by disturbing cell membrane permeability, triggering reactive oxygen 
burst, and interrupting cell homeostasis (Kwak et al. 2011). Other studies have indicated that DAPG treatment results in the loss of mitochondrial membrane potential (Gleeson et al. 2010; Troppens et al. 2013). The DAPG biosynthesis locus includes two operons, phlACBDE and $p h l F$, which function in synthesis, export, and regulation of the antibiotic (Bangera and Thomashow 1999). The product of $p h l D$ is responsible for the synthesis of monoacetylphloroglucinol (MAPG), which is then converted to DAPG through the action of enzymes encoded by phlA, phlC, and phlB (Yang and Cao 2012). Yang et al. (2018) reported that production of DAPG was the primary mechanism by which strain Q8r1-96 reduced the germination of wheat seeds when applied at a dose of $10^{6} \mathrm{seed}^{-1}$ or higher.

Although it is generally accepted that the pathogenicity of "quasi" (minor) pathogens is modulated by environmental conditions, the plant genotype, presence of wounds, and the pathogen dose, the exact mechanism of this phenotype remains poorly understood (Cho et al. 1975). Accordingly, the objective of our research was to determine if Q8r1-96, which is typical of strains responsible for TAD in the PNW, is pathogenic on tomato as are other P. brassicacearum strains, and secondly, to gain insight into the mechanism of pathogenicity of $P$. brassicacearum Q8r1-96. We show that Q8r1-96 and several closely related strains of the $P$. fluorescens complex are quasi-pathogens of tomato. We also show that a mutant of Q8r1-96 deficient in DAPG production was significantly and consistently reduced in the ability to rot tomato fruits as compared with the wild type, suggesting that DAPG production is an important determinant of the pathogenicity of $P$. brassicacearum on tomato.

\section{Materials and Methods}

Bacterial strains and mutants. The phenotypes and source of bacterial strains used in this study are summarized in Table 1.
P. brassicacearum Q8r1-96 was isolated from the rhizosphere of wheat grown in soil from a field near Quincy, WA in the state of take-all decline (Raaijmakers and Weller 1998). The other DAPGproducing Pseudomonas strains have been previously described by McSpadden Gardener et al. (2000) and Weller et al. (2008). The study employed three type III secretion system (T3SS) mutants of Q8r1-96, Q8r1-96 0 OPQR, Q8r1-96rscV, and Q8r1-96rspL, which have been previously described (Mavrodi et al. 2011; Yang et al. 2018). The study also used the isogenic mutant Q8r1-96phID, in which the key DAPG biosynthesis gene phlD was interrupted by the insertion of the kanamycin resistance gene cassette (Yang et al. 2018).

To construct Q8r1-96acc, the 1,033-bp ACC deaminase ( $a c d S$ ) gene of $P$. putida UW4 (Glick 1995) was amplified by PCR with primers acc1 (5'-ATA TAC ATA TGA ACC TGA ATC GTT TTG-3') and acc2 (5'-AAA AAA GCT TAG CCG TTG CGA AAC-3') and KOD DNA polymerase (Millipore Sigma, Burlington, MA). The amplicon was digested with NdeI and HindIII and cloned in gene expression vector pCYB2 (New England Biolabs, Ipswich, MA) under the control of $\mathrm{P}_{t a c}$ promoter and ribosome binding site (RBS). The acdS gene together with $\mathrm{P}_{t a c}$ and RBS was then reamplified using nested PCR with primer sets prnF $\left(5^{\prime}-\mathrm{CTG}\right.$ TTG ACA ATT AAT CAT CGG CTC GTA TAA TG-3') - accR (5'-AGC TGG GTT CTA GCC GTT GCG AAA CAG GAA G-3') and prn2F (5'-GGG GAC AAG TTT GTA CAA AAA AGC AGG CTC TGT TGA CAA TTA ATC-3') - 2R (5'-GGG GAC CAC TTT GTA CAA GAA AGC TGG GTT CTA-3') and cloned into the Gateway entry plasmid vector pMK2010 (House et al. 2004) with BP Clonase II (Thermo Fisher Scientific, Waltham, MA) and single-pass sequenced to confirm the absence of mutations. The promoter-RBS-acdS fusion was then swapped into pBK-mini-Tn7 $\Omega \mathrm{Gm}-c c d B$ (a Gateway

Table 1. Strains used in this study

\begin{tabular}{|c|c|c|}
\hline Strains & Characteristics $^{\mathrm{z}}$ & Source or reference \\
\hline P. brassicacearum $\mathrm{Q} 8 \mathrm{r} 1-96$ & $\begin{array}{l}\text { Wheat rhizosphere isolate from Quincy, WA; } \\
\text { DAPG+; Rif }{ }^{\mathrm{r}} \text {; Genotype D }\end{array}$ & Raaijmakers and Weller 1998 \\
\hline Q8r1-96 OPQR & $\begin{array}{l}\text { T3SS mutant of Q8r1-96, } \Delta(r s p O P-r s c Q R):: \\
\text { aacC1; DAPG+; Rif }{ }^{\mathrm{r}} ; \mathrm{Gm}^{\mathrm{r}}\end{array}$ & Mavrodi et al. 2011 \\
\hline Q8r1-96rspL & $\begin{array}{l}\text { T3SS mutant of Q8r1-96, rspL::aph; DAPG+; } \\
\text { Rif }{ }^{\mathrm{r}} \text {; Kan }{ }^{\mathrm{r}}\end{array}$ & Mavrodi et al. 2011 \\
\hline Q8r1-96rscV & $\begin{array}{l}\text { T3SS mutant of Q8r1-96, rscV::aph; DAPG+; } \\
\text { Rif }{ }^{\mathrm{r}} ; \mathrm{Kan}^{\mathrm{r}}\end{array}$ & Mavrodi et al. 2011 \\
\hline Q8r1-96phlD & $\begin{array}{l}\text { DAPG-deficient (DAPG-) mutant of Q8r1- } \\
\text { 96, phlD::aph; Rif }{ }^{\mathrm{r}} ; \mathrm{Kan}^{\mathrm{r}}\end{array}$ & Yang et al. 2018 \\
\hline Q8r1-96acc & $\begin{array}{l}\text { The mini-Tn7 } \Omega \mathrm{Gm}-\mathrm{P}_{\mathrm{tac}} a c d S \text {-carrying } \\
\text { derivative of Q8r1-96 that constitutively } \\
\text { expresses ACC deaminase; DAPG+; Rif }{ }^{\mathrm{r}} \text {; } \\
\mathrm{Gm}^{\mathrm{r}}\end{array}$ & This study \\
\hline$P$. protegens $\mathrm{Pf}-5$ & $\begin{array}{l}\text { Cotton rhizosphere isolate from Texas; } \\
\text { DAPG+; Genotype A }\end{array}$ & Loper et al. 2012 \\
\hline P. fluorescens Q2-87 & $\begin{array}{l}\text { Wheat rhizosphere isolate from Quincy, WA; } \\
\text { DAPG+; Genotype B }\end{array}$ & Mavrodi et al. 2001 \\
\hline Pseudomonas sp. STAD384 & $\begin{array}{l}\text { Wheat rhizosphere isolate from Stillwater, } \\
\text { OK; DAPG+; Genotype C }\end{array}$ & McSpadden Gardener et al. 2000 \\
\hline P. brassicacearum L5.1-96 & $\begin{array}{l}\text { Wheat rhizosphere isolate from Lind, WA; } \\
\text { DAPG+; Genotype D }\end{array}$ & Raaijmakers and Weller 2001 \\
\hline Pseudomonas sp. Q2-2 & $\begin{array}{l}\text { Wheat rhizosphere isolate from Quincy, WA; } \\
\text { DAPG+; Genotype E }\end{array}$ & McSpadden Gardener et al. 2000 \\
\hline Pseudomonas sp. JMP6 & $\begin{array}{l}\text { Wheat rhizosphere isolate from the } \\
\text { Netherlands; DAPG+; Genotype F }\end{array}$ & McSpadden Gardener et al. 2000 \\
\hline Pseudomonas sp. FF1R18 & $\begin{array}{l}\text { Wheat rhizosphere isolate from Fargo, ND; } \\
\text { DAPG+; Genotype G }\end{array}$ & McSpadden Gardener et al. 2000 \\
\hline Pseudomonas sp. FFL1R22 & $\begin{array}{l}\text { Wheat rhizosphere isolate from Fargo, ND; } \\
\text { DAPG+; Genotype J }\end{array}$ & McSpadden Gardener et al. 2000 \\
\hline Pseudomonas fluorescens $1 \mathrm{M} 1$ & $\begin{array}{l}\text { Wheat rhizosphere isolate from Lind, WA; } \\
\text { DAPG+; Genotype L }\end{array}$ & Raaijmakers and Weller 2001 \\
\hline Pseudomonas sp. D27B1 & $\begin{array}{l}\text { Wheat rhizosphere isolate from the } \\
\text { Netherlands; DAPG+; Genotype M }\end{array}$ & McSpadden Gardener et al. 2000 \\
\hline
\end{tabular}

${ }^{\mathrm{z}}$ Rif $^{\mathrm{r}}$, rifampicin resistance; $\mathrm{Kan}^{\mathrm{r}}$, kanamycin resistance; $\mathrm{Gm}^{\mathrm{r}}$, gentamicin resistance; aph, aminoglycoside $3^{\prime}$-phosphotransferase; aacC1, gentamicin acetyltransferase 3-1; T3SS, type III protein secretion system; DAPG, 2,4-diacetylphloroglucinol; ACC deaminase, 1-aminocyclopropane-1-carboxylate deaminase. 
destination vector derived from $\mathrm{pBK}-$ mini-Tn7 $\Omega \mathrm{Gm}$ with $c c d B$ $\mathrm{Cam}^{\mathrm{r}}$ cassette flanked by attR1 and $a t t \mathrm{R} 2$ sites) using LR Clonase II (Thermo Fisher Scientific). The construct was then introduced into Q8r1-96, resulting in the integration of miniTn7 $\Omega \mathrm{Gm}-\mathrm{P}_{\text {tac }} a c d S$ into a neutral chromosomal site and the constitutive expression of ACC deaminase. All strains were routinely cultured in King's medium B (King et al. 1954) and stored as frozen glycerol stocks at $-80^{\circ} \mathrm{C}$.

Determination of the pathogenicity of $P$. brassicacearum in tomato fruits. The pathogenicity of $P$. brassicacearum wild type and its mutants and other DAPG producers on tomato was determined essentially as described by Belimov et al. (2007). Cherry tomato plants (cv. Sweet 100) were grown in plastic pots $(30 \mathrm{~cm}$ diam. $\times 40 \mathrm{~cm}$ deep) filled with Miracle-Gro potting mix (Scotts Miracle-Gro Company, Marysville, $\mathrm{OH}$ ), in a greenhouse at $27^{\circ} \mathrm{C}$ and a dark/light cycle of $12 \mathrm{~h}$. Immature green fruits were picked when they were approximately $2.5 \mathrm{~cm}$ in diameter, surface sterilized by soaking in a solution of $1 \%$ commercial bleach for $5 \mathrm{~min}$, rinsed three times with sterile water, and allowed to air dry. Bacterial suspensions ranging from 0 to $10^{8} \mathrm{CFU} \mathrm{m}{ }^{-1}$ in sterile water with $0.85 \% \mathrm{NaCl}$ were injected $(10-\mu \mathrm{l}$ aliquot) into the central pith of each fruit, with six fruits per treatment and each fruit serving as a replicate. Control fruits were injected with $0.85 \% \mathrm{NaCl}$ in aqueous solution. After 10 days of incubation at room temperature $\left(23^{\circ} \mathrm{C}\right)$ in the dark, the fruits were cut in half and rated for necrosis on a scale of $0-3$ : $0=$ no tissue necrosis; $1=$ light brown necrosis on less than $1 / 3$ of the fruit; 2 = brown necrosis on $1 / 3$ of the fruit; and 3 = brown to black necrosis on more than $1 / 3$ of the fruit. To fulfill Koch's postulates, immature tomato fruits on the vine were injected $\left(10^{7} \mathrm{CFU} \mathrm{ml}{ }^{-1}\right)$ with strain Q8r1-96 and evaluated for necrosis as described above.

Determination of the effects of Q8r1-96 culture filtrates and pure DAPG on tomato fruits. Strains Q8r1-96 and Q8r1-96phlD were inoculated into $2 \mathrm{ml}$ of $\mathrm{KMB}$ broth in test tubes, incubated at $30^{\circ} \mathrm{C}$ with shaking (200 rpm for $48 \mathrm{~h}$ ), and then filtered to remove the bacterial cells $(0.2-\mu \mathrm{m}$ filter, Acrodisc $25 \mathrm{~mm}$ Syringe Filter, Life Sciences). Cell-free filtrates $(10 \mu l)$ were injected into detached

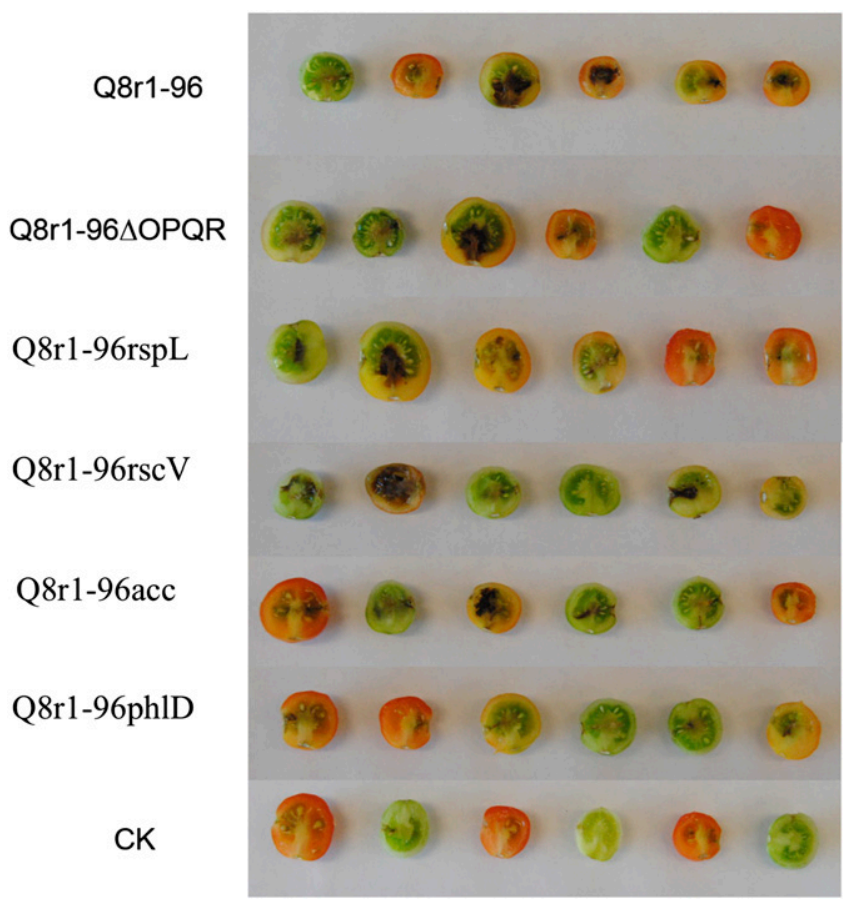

Fig. 1. Cross sections of cherry tomato fruits (cv. Sweet 100) injected with strain Q8r196, DAPG, or T3SS deficient mutants, or a recombinant strain suspended in sterile water with $0.85 \% \mathrm{NaCl}$ at a dose of $10^{8} \mathrm{CFU} \mathrm{ml}^{-1}$. Treatments included wild type Q8r1-96, Q8r1-96 $0 P Q R$, Q8r1-96rspL, Q8r1-96rscV, Q8r1-96acc, Q8r1-96phID, and $0.85 \% \mathrm{NaCl}$ (control). Each treatment had six replicates with each fruit serving as a replicate. Fruits were green when injected and 10 days after infection they were cut in half and rated for disease on a 0-3 scale. tomato fruits one, three, or four times (once each day) as described above. Pure DAPG (Santa Cruz Biotechnology, Inc.) was injected at concentrations of $25 \mu \mathrm{g} \mathrm{ml}^{-1}, 100 \mu \mathrm{g} \mathrm{ml}^{-1}$, and $3 \mathrm{mg} \mathrm{ml}^{-1}$. DAPG was dissolved in methanol $\left(3 \mathrm{mg} \mathrm{ml}^{-1}\right)$ and then further diluted with sterile water. Aliquots $(10 \mu \mathrm{l})$ were injected into immature tomato fruits one, three, or four times as described above.

Determination of the pathogenicity of $P$. brassicacearum Q8r196 in tomato stems. Tomato plants, grown for 30 days in pots with potting mix, were wounded by passing a $0.5-\mathrm{mm}$-diameter syringe needle through the stem at a height of $10-15 \mathrm{~cm}$ above the soil. A $10-\mu \mathrm{l}$ aliquot of a suspension of Q8r1-96 $\left(10^{8} \mathrm{CFU} \mathrm{ml} \mathrm{m}^{-1}\right)$ in $0.85 \% \mathrm{NaCl}$ was then injected into the wound with a pipette and a $10-\mu l$ pipette tip. A $0.85 \% \mathrm{NaCl}$ solution was used as a control. For each experiment, three plants were used for each treatment, and 25 days after injection, a cross-section of the stem was cut with a razor blade to determine the amount of necrosis.

Bacterial colonization of tomato fruits. A $10-\mu 1$ aliquot of a suspension of strain Q8r1-96 $\left(10^{7} \mathrm{CFU} \mathrm{ml}^{-1}\right)$ in $0.85 \% \mathrm{NaCl}$ was injected into immature tomato fruits attached to the vine as described above. After 10 days, tomato fruits were harvested from the vine, cut into small pieces $(2 \times 2 \mathrm{~mm})$, vortexed for $1 \mathrm{~min}$ in $20 \mathrm{ml}$ of sterile water in a 50-ml centrifuge tube, followed by sonication in a water bath for $1 \mathrm{~min}$. Each tomato was processed separately. Bacterial population sizes were determined by the PCR-based dilution-endpoint assay (Bankhead et al. 2016; Yang et al. 2011). Briefly, each tomato washing solution was serially diluted in a 96-well plate $(100 \mu$ added into a well with $200 \mu \mathrm{l}$ of water) and then $50 \mu \mathrm{l}$ of each dilution was transferred to wells of a plate with $200 \mu 1$ of $1 / 3 \times$ KMB broth supplemented with ampicillin, chloramphenicol, cycloheximide, and rifampicin (1/3× $\mathrm{KMB}^{+++}$Rif) (Bankhead et al. 2016; Yang et al. 2011). Growth in each well was determined after 3 days of incubation at room temperature using a Model 680 microplate reader (Biotek). An optical density at $600 \mathrm{~nm}>0.1$ was scored as positive for growth. The population size of Q8r1-96 was based on the final dilution that contained growth and was positive for phlD by PCR using primers (B2BF and BPR4) specific for the DAPG biosynthesis operon (Bankhead et al. 2016; Mavrodi et al. 2012).

Data analysis. Statistical analyses were performed by using appropriate parametric and nonparametric procedures with the STATISTIX 8.0 software (Analytical Software, St. Paul, MN). Mean comparisons among treatments were performed by either the Fisher's protected least significant difference test $(P=0.05)$ or the KruskalWallis all-pairwise comparison test $(P=0.05)$. All experiments were conducted at least twice with similar results.

\section{Results}

Symptoms on tomato fruits and stems caused by $P$. brassicacearum. Strain Q8r1-96 caused significant necrosis and decay of the inside of immature tomato fruits when injected at a dose of $10^{7}$ or $10^{8}$ $\mathrm{CFU} \mathrm{ml}^{-1}$ (Fig. 1). Results were the same for inoculated fruits either attached or removed from the vine. Symptoms ranged from light brown necrosis in the tissue around the injection site to black necrosis and decay of most of the fruit. The amount of necrosis and tissue damage varied considerably among replicate fruits injected at the same time (ratings ranged from 0 to 3 ) and among experiments (Fig. 1). A dose of $10^{6} \mathrm{CFU} \mathrm{ml} \mathrm{m}^{-1}$ caused only browning around the injection site and lower doses caused no symptoms (Table 2). Although not shown here, P. brassicacearum L5.1-96 from a TAD field near Lind, WA (Landa et al. 2003) produced symptoms in tomato fruits identical to those caused by strain Q8r1-96.

Koch's postulates were completed on immature fruits attached to the vine. An initial inoculum dose of $10^{7} \mathrm{CFU} \mathrm{m}{ }^{-1}$ of Q8r1-96 $\left(10^{5}\right.$ CFU per wound) caused tissue necrosis, and the population size of strain Q8r1-96 in fruits increased up to 200-fold at 10 days after inoculation based on quantification by the PCR-based dilutionendpoint method. For example, in three separate fruits, population sizes increased to $\log 6.4,7.2$, and 7.3. Individual bacterial colonies were also isolated from diseased tissue by dilution plating on $\mathrm{KMB}^{+++}$Rif agar. Characteristic colonies of Q8r1-96 were selected from the plates, shown to be positive for phlD by PCR, injected into 
healthy immature fruits as described above, and disease again developed in the immature fruits. Finally, Q8r1-96 was again isolated from the fruits that developed symptoms (Supplementary Fig. S1). Strain Q8r1-96 also consistently caused necrosis in inoculated tomato stems (Fig. 2A).

Basis of the pathogenicity. Derivatives of strain Q8r1-96 deficient in T3SS or DAPG were injected into detached tomato fruits. At doses below $10^{6} \mathrm{CFU} \mathrm{ml}{ }^{-1}$, the tested mutants behaved similarly to the wild-type Q8r1-96 and failed to produce necrosis symptoms in the fruits (Table 2). At higher doses, all tested mutants exhibited reduced ability to rot the fruits as compared with the wild type, but strain Q8r1-96phlD showed the most consistent loss in virulence (Table 3). Because Belimov et al. (2007) suggested that ACC deaminase may help mask the pathogenic properties of $P$. brassicacearum, we also included in our experiments strain Q8r1-96acc, which was engineered to express this enzyme constitutively. However, further tests revealed that Q8r1-96acc did not differ in virulence from the parent strain (Table 2, Fig. 1).

Cell-free culture filtrates of strains Q8r1-96 and Q8r1-96phlD were tested for ability to cause necrosis in detached tomatoes. Fruits injected only once or three times showed no necrosis, but fruits injected with filtrates four times (once on four consecutive days) developed symptoms similar to those caused by their source bacteria, Q8r1-96 and Q8r1-96phlD (Fig. 2C). Pure DAPG injected only once or three times did not cause necrosis typical of that caused by
Q8r1-96, but injection of a dose of $25 \mu \mathrm{g} \mathrm{ml}^{-1}$ or greater for four times caused a necrosis similar to that caused by strain Q8r1-96. However, the methanol solvent used to dissolve the DAPG also darkened the tissue at the site of the injection, but it did not cause a collapse of the tissue like DAPG did (Fig. 2B).

Because our experiments with Q8r1-96phID implicated DAPG as a possible pathogenicity factor, we tested nine other genotypes of DAPG-producing pseudomonads and found that at concentrations of $10^{7}$ or $10^{8} \mathrm{CFU} \mathrm{ml} \mathrm{m}^{-1}$ all strains produced necrosis in detached immature tomato fruits, but the exact degree of damage varied among replicates and individual experiments (Table 4).

\section{Discussion}

Our study was prompted by previous reports claiming that European strains of $P$. brassicacearum, such as Am3R and 520-1, are minor pathogens of tomato capable of causing either growth promotion or necrosis of fruits and stems in a dose-dependent manner (Belimov et al. 2007; Sikorski et al. 2001). We showed that strain Q8r1-96, isolated from wheat grown in the Quincy TAD soil and characteristic of $P$. brassicacearum isolates from PNW TAD soils caused disease in immature tomato fruits and stems with symptoms similar to those reported for strain Am3R (Belimov et al. 2007). In addition, P. brassicacearum strain L5.1-96 isolated from the well-described Lind, WA TAD soil also produced symptoms in tomato identical to those produced by strain Q8r1-96 (data not shown). It is important to note that

Table 2. Necrosis of tomato fruits inoculated with different doses of wild-type Q8r1-96, DAPG, and T3SS deficient mutants, and an ACC deaminase recombinant $^{\mathrm{x}}$

\begin{tabular}{lcccccc}
\hline Dose $^{\mathbf{y}}\left(\mathbf{C F U} \mathbf{~ m l}^{-1}\right)$ & Q8r1-96 & Q8r1-96 $\Delta$ OPQR & Q8r1-96 rspL & Q8r1-96 rscV & Q8r1-96 acc & Q8r1-96 phID \\
\hline 0 & 0 & 0 & 0 & 0 & 0 & 0 \\
$10^{2}$ & 0 & 0 & 0 & 0 & 0 & 0 \\
$10^{4}$ & 0 & 0 & 0 & 0 & 0 & $0.2 \pm 0.2 \mathrm{~A}$ \\
$10^{6}$ & $0.4 \pm 0.2 \mathrm{~A}^{\mathrm{z}}$ & $0.2 \pm 0.2 \mathrm{~A}$ & $0.4 \pm 0.2 \mathrm{~A}$ & $0.4 \pm 0.2 \mathrm{~A}$ & $0 \mathrm{~A}$ \\
$10^{8}$ & $2.2 \pm 0.4 \mathrm{AB}$ & $1.2 \pm 0.4 \mathrm{~B}$ & $1.6 \pm 0.4 \mathrm{~B}$ & $1.2 \pm 0.5 \mathrm{~B}$ & $2.4 \pm 0.2 \mathrm{~A}$ & $1.4 \pm 0.2 \mathrm{~B}$ \\
\hline
\end{tabular}

$\mathrm{x}$ Tissue necrosis was rated on a $0-3$ scale at 10 days after inoculation.

y Each fruit was inoculated once with an aliquot of $10 \mu \mathrm{l}$.

${ }^{\mathrm{z}}$ Means \pm SE in the same row followed by the same letter are not significantly different at $P=0.05$ according to the Kruskal-Wallis all-pairwise comparison test

A

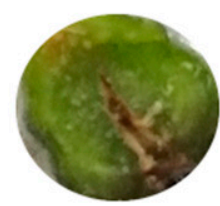

CK

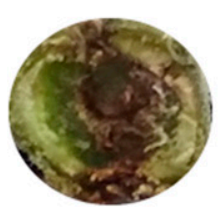

Q8r1-96
C

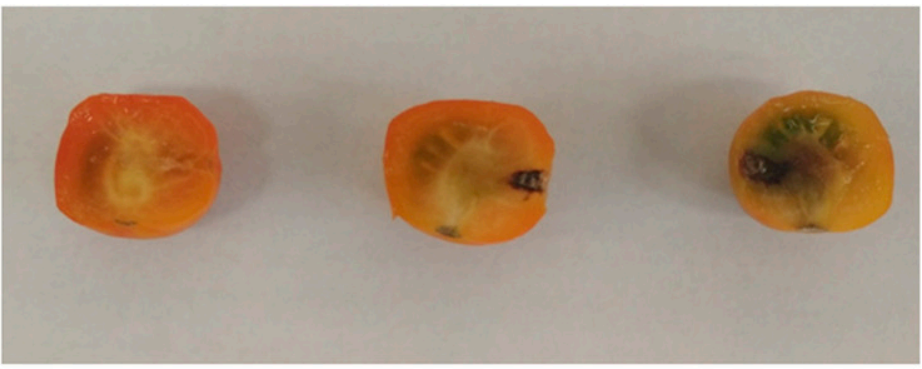

CK
Q8r1-96phID Filtrate
Q8r1-96 Filtrate

B

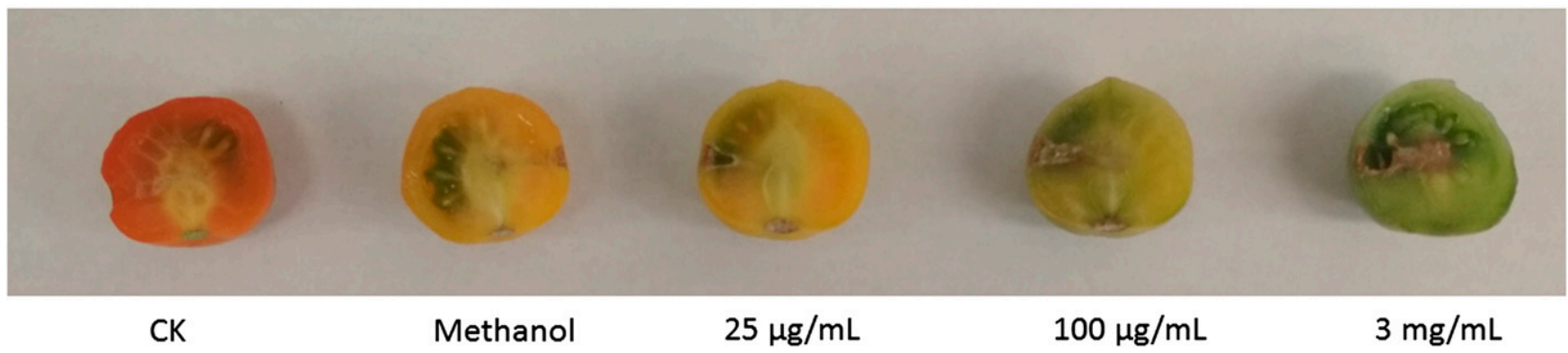

Fig. 2. Necrosis in a tomato stem following injection of strain Q8r1-96 (A); necrosis in detached tomato fruits following four injections of DAPG (B); necrosis in detached tomato fruits following four injections of cell-free filtrates of strains Q8r1-96 and Q8r1-96phID (C). 
phylogenetically, $P$. brassicacearum belongs to the $P$. corrugata subgroup of Pseudomonas (Almario et al. 2017) and P. corrugata naturally infects tomato, causing tomato pith necrosis (Scarlett et al. 1978). We are unaware of any example of $P$. brassicacearum naturally infecting tomato or causing disease. However, if natural infection did occur, the symptoms might be diagnosed as a mild infection by $P$. corrugata.

In general, strains of $P$. brassicacearum from around the world appear to have similar beneficial/deleterious characteristics in their relationship with plants. For example, strain P. brassicacearum 520-1 was first described by Sikorski et al. (2001) as a pathogen of tomato that caused chlorosis, browning, and necrotic lesions of infected plant wounds. Several P. brassicacearum strains from South Australia exhibited take-all disease suppression in wheat infected with Gaeumannomyces graminis and were suggested to be potential biocontrol agents (Ross et al. 2000). P. brassicacearum strain Am3, besides its beneficial and deleterious activity on tomato, promoted root elongation of Indian mustard (Brassica juncea) in vitro and increased root and shoot biomass of rape (B. napus) and pea (Pisum sativum) in pot trials (Belimov et al. 2001; Safronova et al. 2006). Endophytic strains of $P$. brassicacearum have been isolated from potato stem tissue infected with Pectobacterium carotovora (formerly Erwinia carotovora) (Reiter et al. 2003), but the pathogenicity or plant growthpromoting activity of these isolates was not reported.

$P$. brassicacearum strains such as Q8r1-96 and L5.1-96 also show both beneficial and deleterious effects on wheat that are dose and cultivar dependent (Yang et al. 2018). At low or moderate population levels, these rhizobacteria are beneficial to the plant and protect against take-all (Schlatter et al. 2017), but at higher densities they can be deleterious (Kwak et al. 2012; Yang et al. 2018). For example, a population of $10^{5} \mathrm{CFU} \mathrm{g}^{-1}$ root of $P$. brassicacearum is the density needed for control of take-all (Raaijmakers and Weller 1998), and

Table 3. Necrosis of tomato fruits injected with strain Q8r1-96 and its mutants

\begin{tabular}{lcc}
\hline & \multicolumn{1}{c}{ Experiment 1 } & Experiment 2 \\
\cline { 2 - 3 } Treatment $^{\mathbf{x}}$ & Necrosis rating $^{\mathbf{y}}$ & Necrosis rating \\
\hline Q8r1-96 & $2.5 \pm 0.2 \mathrm{~A}^{\mathrm{z}}$ & $2.3 \pm 0.2 \mathrm{~A}$ \\
Q8r1-96 $\mathrm{OPQR}$ & $1.8 \pm 0.3 \mathrm{ABC}$ & $0.8 \pm 0.2 \mathrm{~B}$ \\
Q8r1-96rspL & $1.5 \pm 0.2 \mathrm{BC}$ & $2.2 \pm 0.2 \mathrm{~A}$ \\
Q8r1-96rscV & $2.0 \pm 0.3 \mathrm{AB}$ & $0.8 \pm 0.2 \mathrm{~B}$ \\
Q8r1-96phlD & $1.0 \pm 0.3 \mathrm{C}$ & $1.2 \pm 0.2 \mathrm{~B}$ \\
\hline
\end{tabular}

$\times$ Tomato fruits were injected once with a dose of $10^{8} \mathrm{CFU} \mathrm{ml}{ }^{-1}$.

y Tissue necrosis was rated on a 0-3 scale at 10 days after inoculation.

${ }^{\mathrm{z}}$ Means \pm SE in the same column followed by the same letter are not significantly different at $P=0.05$ according to the Kruskal-Wallis all-pairwise comparison test.

Table 4. Necrosis of tomato fruits injected with different genotypes of DAPGproducing Pseudomonas spp.

\begin{tabular}{lcccc}
\hline & & Experiment $\mathbf{1}$ & & Experiment 2 \\
\cline { 3 - 3 } Strain $^{\mathbf{x}}$ & Genotype & Necrosis rating $^{\mathbf{y}}$ & & Necrosis rating \\
\hline Q8r1-96 & $\mathrm{D}$ & $1.7 \pm 0.3 \mathrm{ABC}$ & \\
FFL1R22 & $\mathrm{J}$ & $1.7 \pm 0.3 \mathrm{ABC}$ & \\
Pf-5 & $\mathrm{A}$ & $1.2 \pm 0.3 \mathrm{BC}$ & $2.3 \pm 0.3 \mathrm{~B}$ \\
Q2-2 & $\mathrm{E}$ & $0.8 \pm 0.2 \mathrm{C}$ & $1.8 \pm 0.2 \mathrm{AB}$ \\
1M1 & $\mathrm{L}$ & $1.7 \pm 0.3 \mathrm{ABC}$ & $1.3 \pm 0.2 \mathrm{~B}$ \\
Q2-87 & $\mathrm{B}$ & $1.2 \pm 0.2 \mathrm{BC}$ & $1.8 \pm 0.2 \mathrm{AB}$ \\
JMP6 & $\mathrm{F}$ & $1.8 \pm 0.2 \mathrm{AB}$ & $1.5 \pm 0.2 \mathrm{AB}$ \\
D27B1 & $\mathrm{M}$ & $1.2 \pm 0.5 \mathrm{BC}$ & $1.5 \pm 0.2 \mathrm{AB}$ \\
STAD384 & $\mathrm{C}$ & $1.7 \pm 0.2 \mathrm{ABC}$ & $1.3 \pm 0.4 \mathrm{~B}$ \\
FFL1R18 & $\mathrm{G}$ & $2.2 \pm 0.4 \mathrm{~A}$ & $2.2 \pm 0.3 \mathrm{~A}$ \\
\hline
\end{tabular}

${ }^{x}$ Tomato fruits were injected with a dose of $10^{8} \mathrm{CFU} \mathrm{ml}^{-1}$.

y Tissue necrosis was rated on a $0-3$ scale.

${ }^{\mathrm{z}}$ Means $\pm \mathrm{SE}$ in the same column followed by the same letter are not significantly different at $P=0.05$ according to the Kruskal-Wallis all-pairwise comparison test. this dose applied to wheat seeds did not reduce the germination rate or root growth. However, greater bacterial doses caused necrosis of roots and stunting of wheat growth in a cultivar dependent manner (Yang et al. 2018). The effect is cultivar-dependent, as the wheat cultivar Buchanan was significantly more susceptible to the deleterious effects of strain Q8r1-96 than the cv. Tara (Yang et al. 2018).

One objective of our study was to determine the mechanism(s) of pathogenicity of $P$. brassicacearum strains from TAD soils. Using mutants of Q8r1-96 deficient in either T3SS or DAPG production, we showed that both significantly reduced the ability to rot tomato fruits as compared with the wild type, but the loss in virulence was consistent only with strain Q8r1-96phlD. Thus, we suggest that DAPG production is an important determinant of the pathogenicity of $P$. brassicacearum on tomato. This conclusion is also supported by results showing that cell-free culture filtrates of strain Q8r1-96 caused necrosis equivalent to the injected cells, but the necrosis caused by Q8r1-96phlD filtrates was much less. In addition, high doses of pure DAPG injected into fruits also caused necrosis. The role of DAPG in the necrosis is not surprising because using Q8r196phlD, Yang et al. (2018) demonstrated that DAPG production was primarily responsible for the phytotoxicity of Q8r1-96 on wheat cvs. Tara, Finley, and Buchanan. DAPG is toxic to a broad spectrum of organisms (Keel et al. 1992; Weller et al. 2008). In plants, DAPG inhibits growth and seed germination (Keel et al. 1992; Maurhofer et al. 1995; Yang et al. 2018) and causes necrotic lesions on roots (Brazelton et al. 2008; Kwak et al. 2012), while DAPG is more active against dicots than monocots (Keel et al. 1992).

DAPG-producing fluorescent pseudomonads are in the $P$. fluorescens complex (Loper et al. 2012) and due to their genetic diversity were previously placed in 22 genotypes that were designated as A-T, PfY, and PfZ (De La Fuente et al. 2006; Landa et al. 2006; Loper et al. 2012; Mavrodi et al. 2001; McSpadden Gardener et al. 2000; Schlatter et al. 2017). DAPG-producing pseudomonads have now been placed in six species in the $P$. fluorescens complex: $P$. protegens, $P$. kilonensis, $P$. gingeri, $P$. thivervalensis, $P$. brassicacearum, and $P$. fluorescens (Almario et al. 2017; Loper et al. 2012; Vacheron et al. 2018); however, the P. fluorescens strains may be moved into one of the other five species (Almario et al. 2017). $P$. brassicacearum strains like Q8r1-96 and L5.1-96, previously called genotype $\mathrm{D}$, share the ability to aggressively colonize wheat roots significantly better than do other DAPG producers (Landa et al. 2003; Raaijmakers and Weller 2001).

Given the apparent role of DAPG in the pathogenicity of Q8r1-96, we tested strains representing nine other genotypes (A, B, C, E, F, G, $\mathrm{J}, \mathrm{L}$, and $\mathrm{M}$ ) isolated from fields throughout the United States and The Netherlands for ability to cause disease in tomato fruits. The finding that all these strains caused symptoms similar to those of Q8r1-96 suggests that pathogenicity in tomato is a common trait of DAPG-producing pseudomonads.

In conclusion, this study expands our understanding of the complexity of the biological activities of $P$. brassicacearum isolated from long-term wheat monoculture soils and the antibiotic that it produces. This bacterium and DAPG play many roles in nature: they are responsible for take-all decline in the PNW (Schlatter et al. 2017); they can be deleterious to wheat germination and root growth (Yang et al. 2018); they induce systemic resistance in Arabidopsis thaliana (Weller et al. 2012); and they can cause disease in tomato. Ultimately, the role that they play in nature will depend on the environment, plant genotype, and bacterial dose or population size.

\section{Literature Cited}

Almario, J., Bruto, M., Vacheron, J., Prigent-Combaret, C., Moënne-Loccoz, Y., and Muller, D. 2017. Distribution of 2,4-diacetylphloroglucinol biosynthetic genes among the Pseudomonas spp. reveals unexpected polyphyletism. Front. Microbiol. 8:1218.

Bangera, M. G., and Thomashow, L. S. 1999. Identification and characterization of a gene cluster for synthesis of the polyketide antibiotic 2,4-diacetylphloroglucinol from Pseudomonas fluorescens Q2-87. J. Bacteriol. 181:3155-3163.

Bankhead, S. B., Thomashow, L. S., and Weller, D. M. 2016. Rhizosphere competence of wild-type and genetically engineered Pseudomonas brassicacearum is affected by the crop species. Phytopathology 106:554-561. 
Belimov, A. A., Dodd, I. C., Safronova, V. I., Hontzeas, N., and Davies, W. J. 2007. Pseudomonas brassicacearum strain Am3 containing 1-aminocyclopropane-1carboxylate deaminase can show both pathogenic and growth-promoting properties in its interaction with tomato. J. Exp. Bot. 58:1485-1495.

Belimov, A. A., Safronova, V. I., Sergeyeva, T. A., Egorova, T. N., Matveyeva, V. A., Tsyganov, V. E., Borisov, A. Y., Tikhonovich, I. A., Kluge, C., Preisfeld, A., Dietz, K.-J., and Sepanok, V. V. 2001. Characterization of plant growth-promoting rhizobacteria isolated from polluted soils and containing 1-aminocyclopropane-1-carboxylate deaminase. Can. J. Microbiol. 47:642-652.

Brazelton, J. N., Pfeufer, E. E., Sweat, T. A., McSpadden Gardener, B. B., and Coenen, C. 2008. 2,4-Diacetylphloroglucinol alters plant root development. Mol. Plant-Microbe Interact. 21:1349-1358.

Cho, J. J., Schroth, M. N., Kominos, S. D., and Green, S. K. 1975. Ornamental plants as carriers of Pseudomonas aeruginosa. Phytopathology 65:425-431.

Cornelis, G. R. 2010. The type III secretion injectisome, a complex nanomachine for intracellular "toxin" delivery. Biol. Chem. 391:745-751.

De La Fuente, L., Mavrodi, D. V., Landa, B. B., Thomashow, L. S., and Weller, D. M. 2006. phlD-based genetic diversity and detection of genotypes of 2,4diacetylpholorogucinol-producing Pseudomonas fluorescens. FEMS Microbiol. Ecol. 56:64-78

Gleeson, O., O'Gara, F., and Morrissey, J. P. 2010. The Pseudomonas fluorescens secondary metabolite 2,4 diacetylphloroglucinol impairs mitochondrial function in Saccharomyces cerevisiae. Antonie van Leeuwenhoek 97:261-273.

Glick, B. R. 1995. The enhancement of plant growth by free-living bacteria. Can. J. Microbiol. 41:109-117.

Haas, D., and Keel, C. 2003. Regulation of antibiotic production in root-colonizing Pseudomonas spp. and relevance for biological control of plant disease. Annu. Rev. Phytopathol. 41:117-153.

House, B. L., Mortimer, M. W., and Kahn, M. L. 2004. New recombination methods for Sinorhizobium meliloti genetics. Appl. Environ. Microbiol. 70: 2806-2815.

Keel, C., Schnider, U., Maurhofer, M., Voisard, C., Laville, J., Burger, U., Wirthner, P., Haas, D., and Défago, G. 1992. Suppression of root diseases by Pseudomonas fluorescens CHA0: importance of the bacterial secondary metabolite 2,4-diacetylphloroglucinol. Mol. Plant-Microbe Interact. 5:4-13.

King, E. O., Ward, M. K., and Raney, D. E. 1954. Two simple media for the demonstration of pyocyanin and fluorescein. J. Lab. Clin. Med. 44:301-307.

Kwak, Y. S., Bonsall, R. F., Okubara, P. A., Paulitz, T. C., Thomashow, L. S., and Weller, D. M. 2012. Factors impacting the activity of 2,4-diacetylphloroglucinolproducing Pseudomonas fluorescens against take-all of wheat. Soil Biol. Biochem. 54:48-56.

Kwak, Y. S., Han, S., Thomashow, L. S., Rice, J. T., Paulitz, T. C., Kim, D., and Weller, D. M. 2011. Saccharomyces cerevisiae genome-wide mutant screen for sensitivity to 2,4-diacetylphloroglucinol, an antibiotic produced by Pseudomonas fluorescens. Appl. Environ. Microbiol. 77:1770-1776.

Landa, B. B., Mavrodi, D. V., Thomashow, L. S., and Weller, D. M. 2003. Interactions between strains of 2,4-diacetylphloroglucinol-producing Pseudomonas fluorescens in the rhizosphere of wheat. Phytopathology 93:982-994.

Landa, B. B., Mavrodi, O. V., Schroeder, K. L., Allende-Molar, R., and Weller, D. M. 2006. Enrichment and genotypic diversity of phlD-containing fluorescent Pseudomonas spp. in two soils after a century of wheat and flax monoculture. FEMS Microbiol. Ecol. 55:351-368.

Loper, J. E., Hassan, K. A., Mavrodi, D. V., Davis, E. W., Lim, C. K., Shaffer, B. T., Elbourne, L. D. H., Stockwell, V. O., Hartney, S. L., Breakwell, K., Henkels, M. D., Tetu, S. G., Rangel, L. I., Kidarsa, T. A., Wilson, N. L., van Mortel, J., Song, C., Blumhagen, R., Radune, D., Hostetler, J. B., Brinkac, L. M., Durkin, S. A., Kluepfel, D. A., Wechter, P. W., Anderson, A. J., Kim, Y. C., Pierson, L. S., Pierson, E. A., Lindow, S. E., Raaijmakers, J. M., Weller, D. M., Thomashow, L. S., Allen, A. E., and Paulsen, I. T. 2012. Comparative genomics of plant-associated Pseudomonas spp.: Insights into diversity and inheritance of traits involved in multitrophic interactions. PLoS Genet. 8:e1002784.

Maurhofer, M., Keel, C., Haas, D., and Défago, G. 1995. Influence of plant species on disease suppression by Pseudomonas fluorescens strain CHA0 with enhanced antibiotic production. Plant Pathol. 44:40-50.

Mavrodi, D. V., Joe, A., Mavrodi, O. V., Hassan, K. A., Weller, D. M., Paulsen, I. T., Loper, J. E., Alfano, J. R., and Thomashow, L. S. 2011. Structural and functional analysis of the type III secretion system from Pseudomonas fluorescens Q8r1-96. J. Bacteriol. 193:177-189.
Mavrodi, O. V., McSpadden Gardener, B. B., Mavrodi, D. V., Bonsall, R. F. Weller, D. M., and Thomashow, L. S. 2001. Genetic diversity of phlD from 2,4-diacetylphloroglucinol-producing fluorescent Pseudomonas species. Phytopathology 91:35-43.

Mavrodi, O. W., Mavrodi, D. V., Parejko, J. A., Thomashow, L. S., and Weller, D. M. 2012. Irrigation differentially impacts populations of indigenous antibiotic-producing Pseudomonas spp. in the rhizosphere of wheat. Appl. Environ. Microbiol. 78:3214-3220.

McSpadden Gardener, B. B., Schroeder, K. L., Kalloger, S. E., Raaijmakers, J. M. Thomashow, L. S., and Weller, D. M. 2000. Genotypic and phenotypic diversity of phlD-containing Pseudomonas isolated from the rhizosphere of wheat. Appl. Environ. Microbiol. 66:1939-1946.

Raaijmakers, J. M., and Weller, D. M. 1998. Natural plant protection by 2,4 diacetylphloroglucinol-producing Pseudomonas spp. in take-all decline soils. Mol. Plant-Microbe Interact. 11:144-152.

Raaijmakers, J. M., and Weller, D. M. 2001. Exploiting genotypic diversity of 2,4diacetylphloroglucinol-producing Pseudomonas spp.: Characterization of superior colonizing P. fluorescens strain Q8r1-96. Appl. Environ. Microbiol. 67:2545-2554

Reiter, B., Wermbter, N., Gyamfi, S., Schwab, H., and Sessitsch, A. 2003 Endophytic Pseudomonas spp. populations of pathogen-infected potato plants analysed by $16 \mathrm{~S}$ rDNA- and $16 \mathrm{~S}$ rRNA-based denaturing gradient gel electrophoresis. Plant Soil 257:397-405.

Ross, I. L., Alami, Y., Harvey, P. R., Achouak, W., and Ryder, M. H. 2000 Genetic diversity and biological control activity of novel species of closely related pseudomonads isolated from wheat field soils in South Australia. Appl. Environ. Microbiol. 66:1609-1616.

Safronova, V. I., Stepanok, V. V., Engqvist, G. L., Alekseyev, Y. V., and Belimov, A. A. 2006. Root-associated bacteria containing 1-aminocyclopropane-1carboxylate deaminase improve growth and nutrient uptake by pea genotypes cultivated in cadmium supplemented soil. Biol. Fertil. Soils 42:267-272.

Scarlett, C. M., Fletcher, J. T., Roberts, P., and Lelliott, R. A. 1978. Tomato pith necrosis caused by Pseudomonas corrugate n. sp. Ann. Appl. Biol 88:105-114

Schlatter, D., Kinkel, L., Thomashow, S. L., Weller, M. D., and Paulitz, T. 2017 Disease suppressive soils: New insights from the soil microbiome. Phytopathology 107:1284-1297.

Sikorski, J., Jahr, H., and Wackernagel, W. 2001. The structure of a local population of phytopathogenic Pseudomonas brassicacearum from agricultural soil indicates development under purifying selection pressure. Environ. Microbiol. 3:176-186.

Tampakaki, A. P. 2014. Commonalities and differences of T3SSs in rhizobia and plant pathogenic bacteria. Front. Plant Sci. 5:1-19.

Troppens, D. M., Dmitriev, R. I., Papkovsky, D. B., O'Gara, F., and Morrissey, J. P. 2013. Genome-wide investigation of cellular targets and mode of action of the antifungal bacterial metabolite 2,4-diacetylphloroglucinol in Saccharomyces cerevisiae. FEMS Yeast Res. 13:322-334.

Vacheron, J., Desbrosses, G., Renoud, S., Padilla, R., Walker, V., Muller, D., and Prigent-Combaret, C. 2018. Differential contribution of plant-beneficial functions from Pseudomonas kilonensis F113 to root system architecture alterations in Arabidopsis thaliana and Zea mays. Mol. Plant-Microbe Interact. 31:212-223

Weller, D. M., Landa, B. B., Mavrodi, O. V., Schroeder, K. L., De La Fuente, L., Bankhead, S. B., Allende-Molar, R., Bonsall, R. F., Mavrodi, D. V., and Thomashow, L. S. 2008. Role of 2,4-diacetylphloroglucinol-producing fluorescent Pseudomonas spp. in the defense of plant roots. Plant Biol. 9:4-20.

Weller, D. M., Mavrodi, D. V., van Pelt, J. A., Pieterse, C. M., van Loon, L. C., and Bakker, P. A. H. M. 2012. Induced systemic resistance (ISR) in Arabidopsis thaliana against Pseudomonas syringae pv. tomato by 2,4-diacetylphloroglucinolproducing Pseudomonas fluorescens. Phytopathology 102:403-412.

Yang, F., and Cao, Y. 2012. Biosynthesis of phloroglucinol compounds in microorganisms. Appl. Microbiol. Biotechnol. 93:487-495.

Yang, M. M., Mavrodi, D. V., Mavrodi, O. V., Bonsall, R. F., Parejko, J. A., Paulitz, T. C., Thomashow, L. S., Yang, H. T., Weller, M. D., and Guo, J. H. 2011. Biological control of take-all by fluorescent Pseudomonas spp. from Chinese wheat fields. Phytopathology 101:1481-1491.

Yang, M. M., Mavrodi, D. V., Thomashow, S. L., and Weller, M. D. 2018 Differential response of wheat cultivars to Pseudomonas brassicacearum and take-all decline soil. Phytopathology 108:1363-1372. 